\title{
Age and size characteristics of alien mollusks Viviparus viviparus $L$. in the coastal thanatocoenosis of Novosibirsk reservoir
}

\author{
Yanygina L.V. ${ }^{1,2}$, Volgina D.D. ${ }^{1}$ \\ ${ }^{1}$ Institute for Water and Environmental Problems SB RAS, Molodezhnaya St., 1, Barnaul, Russia \\ ${ }^{2}$ Altai State University, Lenin St. 61, 656049, Barnaul, Russia \\ E-mail: yan Iv@mail.ru
}

Received: 14.08.2019. Accepted: 26.09.2019

\begin{abstract}
Viviparus viviparus $L$. is the most numerous alien species of the Novosibirsk reservoir. In some parts of the reservoir $V$. viviparus creates settlements with a very high density. After the death of mollusks in the bottom sediments and on the banks of the reservoir, large areas of accumulation of empty shells are formed. Due to their strong structure, the shells are poorly decomposed and can serve as a generalized indicator of the state of the mollusk population over a long time. We analyzed the size and age characteristics of the V. viviparus shells in thanatocenoses of the Novosibirsk reservoir coast. Empty shells of river snails were collected on the shores of the middle (near the village of Chingis, Ordynskoye and in the Karakansky Bay) and the lower (near the village of Borovoye, Bystrovka, Leninsky and in the Berdsky Bay) parts of the Novosibirsk Reservoir in May, 24-26, 2018. Shells height and width were measured with an electronic caliper with an accuracy of $0.1 \mathrm{~mm}$. Age of mollusks was determined by the marks of a winter growth stop on the shell. It is shown that in the thanatocenoses of the middle part and in the bays of the reservoir, shells of young mollusks (the second and third years of life) prevailed. In the lower part of the reservoir, the coastal thanatocoenosis contained larger shells of adult mollusks (fourth and fifth years of life). In general, the most of $V$. viviparus individuals in the Novosibirsk reservoir die before they reach the age limit. It is suggested that the premature death of most river snails can be caused by significant seasonal fluctuations in the water level of the reservoir, during which the littoral is drained.
\end{abstract}

Key words: Invasion; River basin of the Ob; Mollusk; Shells; Thanatocenoses

\section{Introduction}

Viviparus viviparus $\mathrm{L}$. is a West-Palearctic species with a wide distribution area in Europe. In the water bodies of the Ob-Irtysh river basin V. viviparus was first noted in 1994, in the Bukhtarma reservoir (Devyatkov, 2009). In subsequent decades, river snails actively dispersed in the Ob-Irtysh basin. In the late 1990s, V. viviparus was noted in the Novosibirsk reservoir, in 2003 in the Shulba reservoir, in 2009 it was found in a small reservoir of Irtysh river basin near Tobolsk, in 2015 in the river Tura near Tyumen (Devyatkov, 2004; Andreev et al., 2008; Vinarsky et al., 2015; Babushkin and Vinarsky, 2017). All of these habitats of the V. viviparus (except for the Bukhtarminsky and the Shulba reservoirs) are not connected by water. Most likely, V. viviparus was dispersed in the Ob River basin by water transport (Yanygina, 2017).

The establishment of alien species in new waterbodies can be accompanied by a sharp increase in the abundance of invader (Biological ..., 2004). These "environmental explosions" are associated with consumption by invaders a trophic resources, which are not unclaimed by native species, as well as it associated with weak biotic interactions with aboriginal species (for example, weak competition or lack of parasites). When biotic relationships become aggravated, the abundance of an alien species decreases, and the population stabilizes at a new level (Karpevich, 1975).

The establishment of $V$. viviparus in the Novosibirsk reservoir was also accompanied by a sharp increase in abundance and biomass. In the central part of the reservoir, biomass of $V$. viviparus reached $16,000 \mathrm{~g} / \mathrm{m}^{2}$ (Yanygina, Vizer, 2018), and its average values were $811 \mathrm{~g} / \mathrm{m}^{2}$ in 2018 (Yanygina, 2019). V. viviparus is characterized by a relatively long life cycle: according to various literature, it ranges from 4 to 10 years (Jakubik, 2007; Berezkina, Arakelova, 2010). With the death of part of the V. viviparus population and the decomposition of zoomasses, a significant amount of organic substances gets into the water.

In addition, a large number of $V$. viviparus individuals die annually with a periodic reduction of the water level in the reservoir and drying of the littoral. To predict local changes in water quality associated with the entry into the reservoir of organic and biogenic substances during the decomposition of V. viviparus L., it is necessary to know about the dimensional characteristics of dead mollusks. The purpose of this work was to analyze size and age characteristics of $V$. viviparus $\mathrm{L}$. shells, which washed up on the shore of the Novosibirsk reservoir.

\section{Materials and Methods}

Novosibirsk Reservoir is the only reservoir on the Ob river. It's a large lowland reservoir with a length of about $200 \mathrm{~km}$. Its area is $1,070 \mathrm{~km}^{2}$ and its volume is $8.8 \mathrm{~km}^{3}$. Its average depth is $8.3 \mathrm{~m}$. One of the tasks of the reservoir is the seasonal regulation of the Ob river drain. Declining water level in the reservoir occurs in the autumn-winter period, while about $30 \%$ of the reservoir is drained (Long-term dynamics ..., 2014). The material for this work was collected on May 24-26, 2018 in Novosibirsk reservoir near the villages of Chingis, Ordynskoye, Borovoe, in the island near the village of Bystrovka and as well as in the Karakan and Berdsky bays (Table 1). During the period under study the water temperature in different parts of the reservoir varied from 8.6 to $11.0^{\circ} \mathrm{C}$. Empty 
shells of V. viviparus were collected on the banks of the reservoir. At each site, we selected three points (in the center, on the left and right side of the coast), from which all mollusks were collected. The shell height and width were measured using an electronic caliper. When analyzing the dimensional structure, the shells of V. viviparus were sorted into 7 size classes: 1 class - with the shell height less than $10.0 \mathrm{~mm}$; 2 class - 10.1-15.0 mm; 3 class - 15.1-20.0 mm; 4 class - 20.1-25.0 mm; 5 class - 25.1-30.0 mm; 6 class - 30.1-35.0 $\mathrm{mm}$ and 7 class - with the shell height more than $35.1 \mathrm{~mm}$.

Age of mollusks was determined by the marks of a winter growth stop on the shell. A total of 1028 shells of V. viviparus were examined.

Table 1. Coordinates of sampling sites and data regarding the number of collected shells

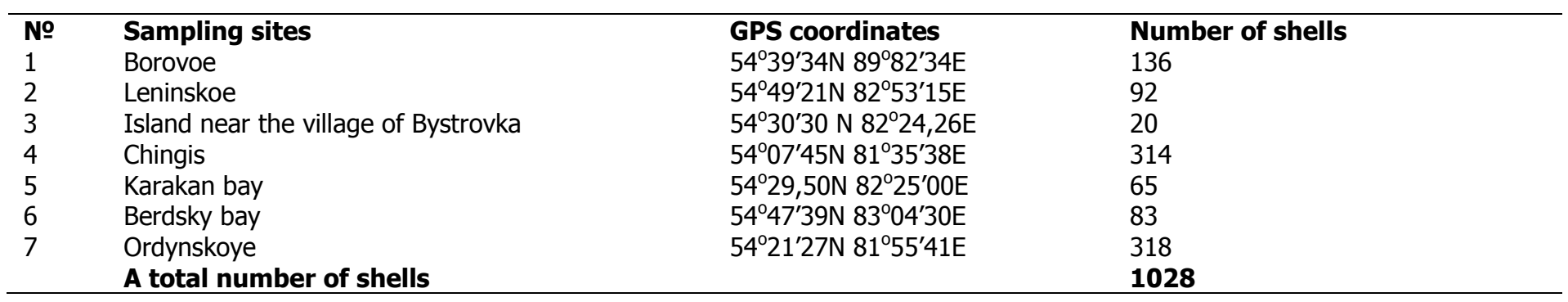

\section{Results and Discussion}

The shell height of $V$. viviparus in thanatocenoses of the Novosibirsk Reservoir varied from $8.8 \mathrm{~mm}$ to $46.2 \mathrm{~mm}$. Shells of the first size class $(<10.0 \mathrm{~mm}$ ) composed $1.75 \%$ of the total number of shells (Figure 1$)$. They were noted only in the areas located in the middle part of the reservoir (near the villages of Chingis and Ordynskoye). Shells of the second size class (10.1-15.0 mm) were also widely represented in the middle part of the reservoir and in the bays, where their share reached $22.9-25.8 \%$ of the total number of shells. Larger shells (6-7 size class) were found mainly in the lower part of the reservoir (near the villages of Borovoye, Bystrovka and Leninskoe). On the sandy beach near the village of Borovoe fraction of large shells reached $45 \%$. In general, in the thanatocenoses of the middle part of the reservoir and in the bays, small shells (2-3 size classes) reach the largest numbers, while in the lower part of the reservoir larger shells (4-7 size classes) were dominated.

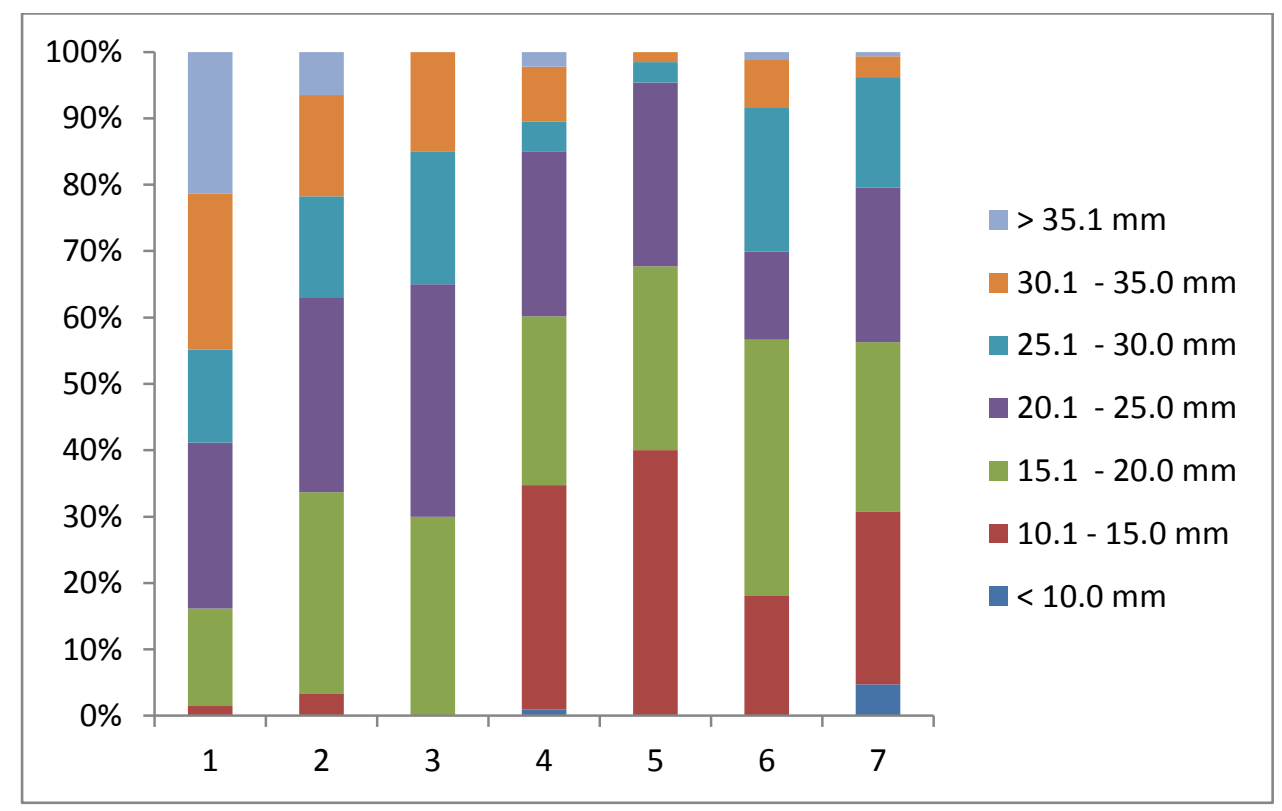

Figure 1. Size structure of Viviparus viviparus $L$. in the thanatocoenosis of Novosibirsk reservoir

Analysis of the age structure of the collected shells showed that the maximum life span of $V$. viviparus in the Novosibirsk reservoir is 6 years, which corresponds to the literature data of other authors for this reservoir (Kuzmenkin, 2014) and for reservoirs in the European part of Russia (Berezkina \& Arakelova, 2010). In general, the age structure of V. viviparus in the thanatocenoses of the Novosibirsk reservoir corresponded to the size structure. In all sampling sites of the reservoir, the minimal fraction (0-1.6\%) were mollusk shells of the first year of life (Figure 2). This may be due to the collection of shells in spring at a relatively low temperature of water, which led to low reproduction rates of $V$. viviparus during this period. In addition, the shells of mollusks of the first year of life are very fragile, they are easily frayed even on sandy soils; therefore, shells of only recently dead individuals are found in thanatocenoses. In general, shells of young mollusks (second (1+) and third (2+) years of life) prevailed in the thanatocenoses of the upper part of the reservoir and bays. V. viviparus can reproduce at the beginning of the third year of life (Berezkina \& Arakelova, 2010), respectively, about $20-30 \%$ of individuals in these areas die before achieving the reproductive age. Shells of more adult mollusks (age $3+-4+$ ) predominate on the coast of the reservoir lower part. 


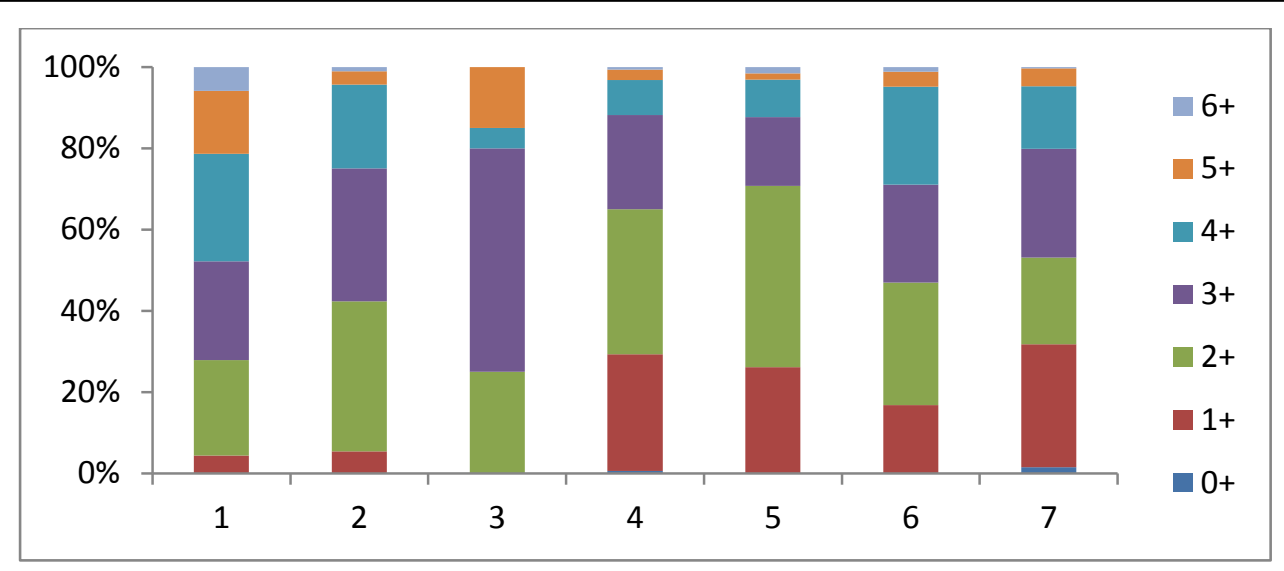

Figure 2. Age structure of Viviparus viviparus L. in the thanatocoenosis of Novosibirsk reservoir

Based on the data obtained in the course of studies on the life span of $V$. viviparus, it should be noted that only a small part of the population of mollusks lives up to its age limit. In the middle part of the reservoir near the village of Chingis and in the Karakan Bay, the share of mollusks that died at the age of 4 years or more is only $12 \%$. And only in the thanatocenoses of the lower part of the reservoir near village of Borovoe the proportion of such mollusks reaches $47.8 \%$. A high proportion of young shells in the thanatocenoses may be associated with a significant decrease in the reservoir water level during the fall-winter empty. In the spring, after the snow melts and before the reservoir is filled to the normal maximum operating level, these parts of littoral dry out, and the mollusks located on them partially die (Vizer, 2011).

\section{Conclusion}

Age and size structure of V. viviparus shells in thanatocoenosis of various parts of the Novosibirsk reservoir indicates about death of a significant part of the population of mollusk didn't reaching the age limit. In the middle part of the reservoir and in the bays, about $20-30 \%$ of dead mollusks are individuals who have not reached the reproductive age. Premature death of mollusks may be associated with significant seasonal fluctuations in the water level of the reservoir, which leads to the draying of the littoral.

The research was performed in the framework of the Federal Project (registration number AAAA-A17-117041210244-5), with partial financial support from the RFBR (project number 18-04-01001).

\section{References}

Andreev, N.I., Andreeva, S.I., Vinarsky, M.V., Lazutkina, E.A., Selezneva, M.V. (2008). Viviparus viviparus (L., 1758) (Mollusca: Gastropoda) is a New Species of Fauna of Novosibirsk Reservoir. Transactions of The International Conference on Present Status of Aquatic Bioresources. Novosibirsk, 118-120. (in Russian)

Babushkin, E.S., Vinarski, M.V. (2017). First finding of the freshwater mollusk Viviparus viviparus (Linnaeus, 1758) in the River Tura (the Tyumen region). Fauna of the Urals and Siberia, 1, 19-24. (in Russian)

Berezkina, G.V., Arakelova, E.S. (2010). The life-cycles and growth of some comb-branchial molluscs (Gastropoda: Pectinibranchia) in the ponds of the European part of Russia. Proceedings of the Zoological Institute RAS, 314 (1), 80-92. (in Russian).

Biological Invasions in Aquatic and Land Ecosystems. (2004). Moscow, Russia: KMK Scientific Press Ltd (in Russian)

Devyatkov, V.I. (2004). Invertebrates - acclimatizers of the Upper Irtysh reservoirs. Ecological problems of the agro-industrial complex: international materials. conf. Almaty, 83-86. (in Russian)

Devyatkov, V.I. (2009). Macrozoobenthos. In O. P. Bazhenova (Eds.) Biocenosis successions of the Bukhtarma reservoir (95-199). Omsk, Russia: Publishing House OmASU. (in Russian)

Jakubik, B. (2007). Size structure and age, mortality and fertility in Viviparus viviparus (L.). Folia Malacol, 15(3), $109-117$.

Karpevich, A.F. (1975). Theory and practice of acclimatization of aquatic organisms. Moscow, Russia: Pischevaya promyshlennost'. (in Russian)

Kuzmenckin, D.V. (2014). Morphometric characteristic and some growth specifications of the snail Viviparus viviparus (L.) in the Novosibirsk reservoir. Altai Zoological Journal, 8, 3-9. (in Russian)

Long-term dynamics of the water-ecological regime of the Novosibirsk reservoir. (2014). Novosibirsk, Russia: Publishing House of the SB RAS. (in Russian)

Vinarski, M.V., Andreev, N.I., Andreeva, S.I., Kazantsev, I.E., Karimov, A.V., Lazutkina, E.A. (2015). Alien mollusk species in the aquatic ecosystems of Western Siberia: A review. Russian Journal of Biological Invasions, 6, 2-19. https://doi.org/10.1134/S2075111715030078

Vizer, A.M. (2011). Zoobenthos of the drainage zone of Novosibirsk Reservoir. Contemporary Problems of Ecology, 4, 50-55. https://doi.org/10.1134/S1995425511010085

Yanygina, L.V., Vizer, A.M. (2018). Peculiarities of invasion of Viviparus viviparus (Gastropoda, Viviparidae) into the Novosibirsk reservoir. Ecological, industrial, energy safety, Sevastopol, 1311-1313. (in Russian)

Yanygina, L.V. (2019). Community-level effects of a Viviparus viviparus L. (Gastropoda, Viviparidae) invasion in the Novosibirsk reservoir. Limnology. https://doi.org/10.1007/s10201-019-00580-4

Yanygina, L.V. (2017). Pathways of macroinvertebrate invasions in the river Ob basin (West Siberia). Limnology, 18, $243-249$. https://doi.org/10.1007/s10201-016-0511-x

\section{Citation:}

Yanygina L.V., Volgina D.D. (2019). Age and size characteristics of alien mollusks Viviparus viviparus L. in the coastal thanatocoenosis of Novosibirsk reservoir. Ukrainian Journal of Ecology, 9(3), 412-414.

\begin{tabular}{|l|l}
\hline$(\mathrm{cc}) \mathrm{Br}$ \\
$\mathrm{Br}$
\end{tabular} 